Data Article

\title{
First high-quality genome assembly data of sago palm (Metroxylon sagu Rottboll)
}

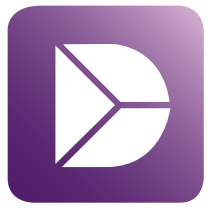

\section{Leonard Whye Kit Lim ${ }^{a}$,*, Melinda Mei Lin Lau ${ }^{a}$, Hung Hui Chung ${ }^{\mathrm{a}, *}$, Hasnain Hussain ${ }^{\mathrm{b}}$, Han Ming Gan ${ }^{\mathrm{c}, \mathrm{d}}$}

\author{
a Faculty of Resource Science and Technology, Universiti Malaysia Sarawak, 94300 Kota Samarahan, Sarawak, \\ Malaysia \\ ${ }^{\mathrm{b}}$ Centre for Sago Research (CoSAR), Faculty of Resource Science and Technology, Universiti Malaysia Sarawak, \\ 94300 Kota Samarahan, Sarawak, Malaysia \\ ${ }^{\mathrm{c}}$ GeneSEQ Sdn Bhd, Bukit Beruntung, 48300 Rawang, Selangor, Malaysia \\ ${ }^{\mathrm{d}}$ Centre for Integrative Ecology, School of Life and Environmental Sciences, Deakin University, Geelong, Victoria, \\ Australia
}

\section{A R T I C L E I N F O}

\section{Article history:}

Received 18 November 2021

Accepted 4 January 2022

Available online 6 January 2022

\section{Keywords:}

Metroxylon sagu

Sago palm

Genome annotation

Starch synthesis

\begin{abstract}
A B S T R A C T
The sago palm (Metroxylon sagu Rottboll) is a tropical halophytic starch-producing, economically important crop palm mainly located in Southeast Asian countries. Recently, a genome survey was conducted on this palm using the Illumina sequencing platform, with a very low (21.5\%) BUSCO genome completeness score, and most of them ( 78\%) are either fragmented or missing. Thus, in this study, the sago palm genome completeness was further improved with the utilization of the Nanopore sequencing platform that produced longer reads. A hybrid genome assembly was conducted, and the outcome was a much complete sago palm genome with BUSCO completeness achieved at as high as $97.9 \%$, with only $\sim 2 \%$ of them either fragmented or missing. The estimated genome size of the sago palm is $509,812,790$ bp in this study. A sum of 33,242 protein-coding genes was revealed from the sago palm genome and around $96.39 \%$ of them had been functionally annotated. An investigation on the carbohydrate metabolism KEGG pathways
\end{abstract}

Abbreviations: aa, amino acid; bp, base pair; BUSCO, Benchmarking Universal Single Copy Orthologs; KEGG, Kyoto Encyclopedia of Genes and Genomes; SDS, Sodium dodecyl sulfate.

* Corresponding authors.

E-mail addresses: 19010029@siswa.unimas.my (L.W.K. Lim), hhchung@unimas.my (H.H. Chung).

Social media: (L.W.K. Lim) 